\title{
The Development of Managerial Assumptions about Human Nature in China: A Tale from Quanzhou
}

\author{
Yi-Bing Zhang, Siew-Huat Kong \\ University of Macau, Macau, China
}

\begin{abstract}
How managers' knowledge and beliefs of human nature are formed and manifested has not been fully explored in the context of Chinese society going through rapid transition nowadays. And yet this could be the missing link in our discourse on Chinese managers. Based on a qualitative study conducted in Quanzhou, China, this study found certain assumptions of human nature that are deeply embedded in their managers' intellectual framework, which in turn guide their managerial behaviours in diverse aspects of their work. Unless the managers are prepared to examine their own thoughts, especially those at the sub-conscious level, they would remain prisoners of their own thought, and all the efforts directed at transforming managers would be seriously compromised.
\end{abstract}

Keywords: assumptions, China, human nature, manager’s intellectual framework, Quanzhou

\section{Introduction}

Managerial assumption is a key component of some influential theories, including theory-in-use (Argyris, 1982), mental model (Senge, 2006), underlying assumption (Schein, 2004), and cognitive map (Spradley, 1979). Of the many managerial assumptions, those concerning human nature are important in determining and disciplining the social life and mental space of a manager. Managerial behaviour is shaped by these assumptions even while structuring them, either consciously or unconsciously (Schein, 2004).

In recent decades, among the various conceptual models of human nature that were widely employed in the formation of economic and social policies, it has been the self-interested homo economicus (Smith, [1776] 1986) model that continues to dominate the landscape. Humans, as defined by Adam Smith, are rational-economic actors and only care about their own self-interest. Although the Hawthorne studies (Roethlisberger \& Dickson, 1939) that appeared a little later emphasized the social dimension of human beings at workplace, they remained in the shadow of homo economicus, as did the concept of self-actualization introduced by Maslow (1954) and Argyris (1964). However, the impact of homo economicus on Chinese managers is yet to be explored.

In later studies, McGregor (1985) suggested that in the management of human resources, the assumptions and theories about human nature at any given time limit innovation in the workplace. But more importantly, managers' assumptions of human nature shape their behaviour. For example, in accepting the assumptions of Theory $\mathrm{X}$, there is no reason to devote time, effort, or money to discovering how to realize human potentialities. On the other hand, if we accept assumptions like those of Theory Y, we will be challenged to innovate, to

Yi-Bing Zhang, Ph.D. Candidate, Faculty of Business Administration, University of Macau.

Siew-Huat Kong, Ph.D., Associate Professor, Faculty of Business Administration, University of Macau. 
discover new ways of organizing and directing human effort. Ouchi (1981) proposed Theory $\mathrm{Z}$ which is a more humanized, holistic view of the organization and its members. Theory $M$ is supposedly used to represent the Chinese way of management, which adopts the Confucian value system and emphasizes concepts such as moderation (zhongyong), human mind, and human resources (Zeng, 2006).

Understandably, managers' assumptions about human nature are an important predictor of their leadership style and behaviours (Sabanci, 2008). Interestingly, such assumptions help shape their beliefs about human nature itself (Frank, 1988). Differences in managers' beliefs result in differences in how they manage people and organizations (Schein, 2004). Today, economics has evidently won the battle for theoretical hegemony in academia and society as a whole; its dominance is becoming stronger by the day, and it is spreading rapidly across the globe from its Western origins (Ferraro, Pfeffer, \& Sutton, 2005). Accordingly, economic man-a creature who pursues his self-interests in a rational and self-maximizing manner-as an assumption has a strong impact on the formation of many management policies and behaviours.

To be sure, when managers adopt the assumption of self-interested human beings from the classical economic models, they aim for nothing less than the unleashing of competitive forces in people and in organizations (Ferraro, Pfeffer, \& Sutton, 2005), emphasizing extrinsic incentives in management design, and readily accepting the war for talent and talent management (Heath, 1999). Regardless of whether managers regard this situation as ideal or otherwise, it is in their interest to understand their assumptions about human nature that are guiding their daily behaviours as managers. This study aims to contribute to this understanding.

\section{Managerial Assumptions About Human Nature in the Context of China}

Chinese culture and values, and especially Confucianism, also play a significant role in Chinese enterprise management (Hofstede \& Bond, 1988; Zhang \& Simon, 2009). Embedded within every culture is a certain assumption of human nature. For example, Mencius says, "Man's nature is endowed with feelings which impel it toward the good. That is why I called it good” (Legge, 1970). Hahn and Waterhouse (1972) argue that Mencius's observation about human nature became a central thought of Confucianism, and in fact was the cornerstone for the later dominance of Confucian moral philosophy. The Chinese philosopher Gaozi, by contrast, argued that human nature is originally morally "neutral" (Yu, 2007). McGreal (1995) suggests that both these views are contested by their contemporary Chinese philosopher Xunzi, who held that human nature is innately evil but human beings are capable of becoming good through the civilizing activities of teachers and rulers.

Despite their different perceptions about human nature, both Xunzi and Confucius stress the importance of education, that is, people can be educated to be good. Chen (2000) suggested that, as traditional values focus on the cultivation of the individual, a Confucian manager is supposed to be kind, and to listen to the persons he manages in order to improve their daily life. He will be evaluated on his dedication to the company and the employees. Trustworthiness and loyalty are some of the qualities that indicate a good person, which is why they are very important for Chinese managers. However, what is often not made explicit is what kinds of qualities are considered desirable in certain settings - and whether or not those human qualities can be nurtured is a particular belief or assumption about human nature that the managers themselves uphold.

Since the open-door policy in 1978, China has achieved a level of rapid economic development that has impressed many observers. In the business field, however, corporations and managers are often accused of low cultural quality (wenhuasuzhidi), due to problematic products labeled "made in China" and numerous 
tofu-dregs projects (doufuzhagongcheng) (Osburg, 2013). There appears to be a prevailing lack of trust, confidence, and reassurance about Chinese products and the Chinese way of managing business. How do their managerial assumptions about human nature come into the picture here will be a goal of this investigation.

\section{Reasons for This Study}

The main goals of this study are to help the discourse move beyond the often superficial, fragmented, or distorted conceptions of human nature that circulate widely today (Bohm, 1994; Schein, 2004), to take a developmental view of human nature (ISGP, 2005), and inform the evolving conceptual framework that will guide practitioners in the discourse of management field. This study aims to participate in the reflection on the present economic and social order by investigating into the root causes of its structure and behaviours, and at this very foundation are certain conceptions of human nature. It aims to demonstrate the potency of managerial assumptions about human nature - this concept permeates all facets of organizational and individual life despite how little people actually are conscious of it. In other words, the aim is to show the expression of human nature in the context of Chinese organizations, which are undergoing transformation themselves.

\section{Research Questions}

The present study is based the premises that: "The reality of man is his thought, not his material body" (Abdu'l-Bahá, 1969, p. 17); as a corollary, the management system of a human organization is animated and sustained by the collective thoughts that permeate that entity (Bohm, 1994); further, there are mutual interactive and inter-dependent relationships between the thoughts of the individual and the collective (Effendi, 1933). As such, this article will focus on the cognitive aspect of management (Argyris, 1976; McGregor, 1985; Schein, 2004; Senge, 2006; Weick, 1995). Specifically, this investigation addresses the following questions:

- What are the different elements of managers' assumptions about human nature?

- How did the assumptions about human nature come into being, and how are they giving shape to the current structure of management and managers' behaviour?

\section{Research Methods and Setting}

The areas surrounding Quanzhou have traditionally been considered an economic powerhouse engaging in light manufacturing industry, not dissimilar to other regions in China. This city is a populous urban area in Fujian Province of PRC, which is famous for its business atmosphere and its large number of publicly listed companies. For this city, this is an era of rapid change, and the population is embracing the transition with some level of anxiety about the "new normal", a reading of the current social and economic reality in China by President Xi.

For ease of narrative, the fieldwork is described here from the perspective of one of this article's contributors. I made contact with the informants via classmates, ex-colleagues, friends, and family members. The informants (see Table 1) are from a wide variety of backgrounds, although the majority of them hold positions as middle or senior management in private firms. These firms are of different sizes, from less than one hundred to several hundred employees, in such diverse industries as garments, shoes, or leather manufacturing; cultural and creative products; and real estate development and sales. 
Table 1

Informant Pseudonyms and Background

\begin{tabular}{llllll}
\hline & Pseudonym & Age & Gender & Position and company & Location of interview \\
\hline 1 & Kang Jing & 45 & Male & CFO of a real estate company in Quanzhou & Restaurant \\
2 & Zheng Xin & 42 & Male & Financial Controller of a real estate company & Company \\
3 & Wang Xiang 45 & Male & Vice President of an auto sales company & Company and restaurant \\
4 & Dai Yi & 45 & Male & Owner of a family clothing business & Company and restaurant \\
5 & Liu Jun & 40 & Male & Vice President of a manufacturing company & Company, teahouse, and restaurant \\
6 & Wang Zong & 55 & Male & Owner of a consulting company & Teahouse and restaurant \\
7 & Chen Jin & 47 & Male & Owner and Managing Director of an incense business & Company \\
8 & Zhou Hua & 40 & Female & Assistant Chairman in a leather company & Company, Starbucks, and restaurant \\
9 & Yang Yi & 54 & Male & Chief Financial Official of FZ & Restaurant \\
10 & Shao Sheng & 37 & Male & Managing Director of a biomedical company & Starbucks \\
11 & Yang Feng & 37 & Male & Chief Financial Official of a leather enterprise & Company \\
12 & Lai Chang & 36 & Male & Finance Manager of a listed company & Voice chat in WeChat \\
13 & Lin Jin & 37 & Male & Human Resource Manager of a real estate company & Voice chat in WeChat and restaurant \\
14 & Li Xing & 53 & Male & CFO of a listed leather company & Company and restaurant \\
15 & Cui Lin & 44 & Female & Owner of a furniture manufacturing enterprise & Starbucks \\
16 & Yang Hong & 40 & Male & Vice President of a listed transportation company & Company and restaurant \\
17 & He Sha & 55 & Male & Founder of a private business & Restaurant \\
18 & Liu Hong & 45 & Male & One of my high school classmates & Company and restaurant \\
19 & Ke Hui & 46 & Male & General Manager of a Petro Trading company & Company \\
20 & Lin Rong & 60 & Female & Founder of a landscaping firm & Company \\
\hline
\end{tabular}

The first manager I met was Lin Jin, the human resource manager of a real estate company, introduced by a friend who took the same exam as me several years ago. Lin Jin and my friend are ex-colleagues. Our interview lasted for nearly two hours and Lin Jin felt that my questions helped him to clarify some concepts in his own thinking. Immediately after I interviewed him he introduced me to another friend Zhou Hua, who is also in the field of human resource management. In turn, Zhou Hua introduced me to human resource manager Shi Li immediately after the interview. Managers have their social circle (quanzi). If one becomes a member of a particular quanzi, it is easier to gain the trust of other members. There is always an atmosphere of mutual support or information exchange within the quanzi. One's quanzi can be expanded quickly if one spends enough money and time with other members. After a number of interviews and gatherings, these initial contacts introduced me to their friends, colleagues, relatives, and acquaintances. I received invitations to several banquets with managers of listed companies in Quanzhou. Over the course of my fieldwork, I was also invited to participate in informal teahouse gatherings and even foot massages.

By visiting Quanzhou several times in the winter of 2014 and the summer of 2015, I maintained friendships with several managers. The rapport that transformed these managers from acquaintances into friends was mostly based on trust, emotional compatibility, and a shared sense of personality. The friendships did not seem to correlate with quantifiable variables like income, occupational status, or educational attainment. Some interviews were conducted formally by using an interview guide. Others were longer and did not necessarily follow the sequence of interview questions. Normally the length of an interview was about two hours. In some cases, when I had built a good rapport with the informant, the conversation was longer.

I contacted some of my informants during my second and third visits to Quanzhou. I also added them to my WeChat contact list and kept in touch with them by sharing information on this platform or sending 
WeChat messages to each other. In this article, I will focus particular attention on these managers to illustrate how their assumptions about human nature are formed and manifested in their individual and organizational life. A few informants I interviewed speak the Quanzhou variant of the Minnan dialect (Minnan is the southern part of Fujian province). The majority of informants used mandarin (putonghua) to communicate.

\section{Information Collection and Analysis}

There were in total around 300 hours of in-depth interviews and participant observation. As well as data collected from interviews and observation, some sources of documentary evidence were also considered, such as companies' annual reports, employee manuals, company policies, mission and values statements, company magazines, official websites, news outlets, and newspaper reports. Most of the interviews were recorded using my cellphone. Each of the 20 interviews was transcribed into a separate Word file. These files were then merged into a single file and stored in my computer. Following Agar (1996), a summary of the key points regarding observations, conversations, interpretations, and suggestions for future information was drawn up. The final written language of transcription was Chinese, both Mandarin and the Minnan dialect. It took around 140 hours to complete the transcription of the 20 interviews. The result of initial coding provided thematic analysis of the interview transcript using nodes. Software was used to help in the process of data indexing, managing, and interpreting. The nodes were examined by categorizing them.

In qualitative inquiry, whether the perspective taken by the researcher is native or scholarly, and whether the positioning of the researcher is one of involvement or detachment, will have a big impact on validation of the fieldwork (Powdermaker, 1967). All meanings are at least partly constructed by observers and participants and hence multiple interpretations are unavoidable in organizations and other social systems (Eisenberg, 1984; Powdermaker, 1967). In order to improve this study's validity, prolonging the engagement in interviews and observation was considered. Triangulation through using ethnographic interviews, informal interviews, stories, document analysis, and participant observations was used to reduce misunderstanding and distortion. Also, showing field notes to informants for checking the correctness of data collected was also a vital part of this fieldwork.

\section{Findings}

The findings of the study are discussed next, grouped around five different themes, as below.

\section{The Emotional Security Offered by Physical Properties}

When I started my fieldwork in Quanzhou, the first thing that caught my eye was a row after rows of commercial housing and offices. However, most of these buildings were empty. But, why is there an increasing number of urban households owning more than one home and why is there a compulsion for them to purchase even more properties? Many informants told me that they have to pay a very high monthly mortgage. Mr. Yang Hong, the vice president of a listed company, said:

After year 2000, I bought two apartments that are more than 200 square meters. I feel more secure by possessing more properties. Now, I have to pay the bank mortgage of more than 10,000 yuan per month, which is the major part of my family's monthly income.

Mr. Yang Hong's situation is far from unique in China. Studies indicate that the housing price index to annual income ratio has reached an average of 8.5 in most Chinese cities, and exceeds 14 in coastal cities. These figures can be compared to Spain or the United States, where the ratio peaked at 8 at the highest point of 
their respective real-estate bubbles (Ding, 2012).

Historically, Chinese people like to own property. The dream of property ownership is deeply established in their minds (La Grange \& Pretoruis, 2000). Chinese parents are supposed to buy, build, or redecorate a house for their son before his marriage. Many informants take the view that it is necessary to buy a property in the city for their children, either for the convenience of their schooling or for their marriage. The majority of informants have two apartments, one for themselves and another one preparing for their child. Due to the single-child policy after 1978, many informants have only one child, and they hope this child will join the elite club in the future through their material investment (Fong, 2007). And supporting this move is their assumption that material wealth can offer the security that these desperate souls are craving for. Paradoxically, accumulating personal wealth quietly and with a low profile is often a position taken by managers. Many managers constructed big and lavish houses in their hometown, and not in the town which they work and socialize. This might be evidence of the view that money should not be exposed (caibuwailu), which is consistent with values such as modesty, zhongyong, and hanxu (Dardes, 1991; Li, 2013; Zeng, 2006).

\section{Committed Capitalists in a Socialist Society}

My informants are adamant that humans are motivated primarily by self-interested pursuits and that opportunities and resources are limited. The majority of informants make the assumption that human beings are animals. In a gathering with five managers, I asked their view about human nature. All of them agreed that humans are animals, and basically self-seeking. Some of them mentioned Maslow's (1954) theory in terms of physiological and safety needs, while others mentioned that the competitive society forces them to act in a self-interested manner. The majority of managers' responses reflect the fundamental premises of the importance of a physical and material life. Mr. Shao Sheng, the managing director of a biomedical company, said:

Humans are animals. This is unquestionable. We need food, water, sleep, and fresh air for survival. This is exactly like the needs of an animal. If you don’t have enough food or drink you will die. Our society is very pragmatic. We have to compete for survival. Protecting ourselves is the most important thing. Although I am the boss, I have to sell the products myself, and maintain a good relationship with clients. Otherwise the company would not be able to survive, the employees would have no food, and their daily necessities cannot be ensured (meifanchi).

It is also premised that human happiness is best pursued through material consumption or sensual pleasures. Mr. Wang Xiang, the VP of an auto sales company, said:

After work I like to go to Karaoke. If I go to Macau, I cannot control myself also, as gambling is so attractive. So I dare not go to these places (without enough money). Thus I have to satisfy myself with other interests, such as drinking alcohol. Because of this, I opened a restaurant. I can entertain with my friends frequently in my restaurant.

Acting on the-conscious or unconscious—assumption that the human is living in the animal realm, many managers enjoy banquets, karaoke, teahouses, playing cards, gambling, or taking care of mistresses. The Confucian philosopher Mencius reasserted that the desire for food and sex is part of human nature (shise, xingye). Although this saying has multiple interpretations, managers tend to use it as a justification in support of their daily behaviour. If the human is basically animal-like, living for physical desires such as sex and food is, without a doubt, the major part of a person's life. 


\section{Making Money: The Successful Ones Are Making It Quick and Big}

It is taken for granted that money is the most important thing in organizational and individual life. For example, the manager respondents believe that employees work only for money. Mr. Lai Chang, the finance manager of a listed company, said:

We are normal people and our capacity is limited. It doesn't do us any good to exaggerate about one's own importance. We cannot have an impact on the society as a whole. What I can do is to earn more money, get along well with my family. Making money or material achievement is the only means I can use to compare with my friends.

\section{Mr. Wang Xiang added:}

Of course, those employees who really want money or who lack money are the easiest to manage. As an example, during days around Mid-autumn Festival, the company dispenses festival allowances for each department to celebrate the festival together. However, some departments choose to give the money to each individual, as they like cash rather than getting together with colleagues. In order to attract more talented personnel, we always provide competitive remuneration packages in our recruiting practices.

When I asked him what would make him happy, he added:

What makes me happy? The answer is money. What makes me upset? The answer is money, too. What we'd like to celebrate in the company is when we obtain new orders and make more profit from our clients.

That humans are incorrigibly competitive seems to be a doctrine strongly held by the managers as well. To compete with each other is a natural thing. Many informants take the view that material achievement can also be accomplished by reaching higher-ranking positions in a company. To be president, CEO, VP, CFO, or a similar position is the dream of many managers. Mr. Lai Chang explained:

I am facing the bottleneck of my career. As a CFO, I am already at the top of my finance and accounting career. However, now I am very depressed. I can see the success of my friends. For example, one of them became the VP of investment in a large company. The other friend is the CFO of a listed company. Maybe these are the two future career paths for me. However, I feel embarrassed in the current situation. If I choose to leave the company now, that means I have to face some risks. To join a new company, I have to learn the culture of the new company and start a new career from zero. If I choose to stay, I would feel a mental imbalance when I see the achievement of my classmates. Frankly, I am losing the inner peace in my heart.

Mr. Wang Xiang often posts job vacancies in the company on the WeChat platform; the vacancies include CEO, vice chairman, or marketing director, among others, with an annual remuneration package of around several million yuan for some of them. Later he explained that the advertisement is merely an imitation of some companies' practice and the high remuneration mentioned is meant to catch people's attention only. However, he promises that they will at least provide competitive packages compared with other companies in the same industry. Mr. Wang's pragmatic point of view is not unique to China, as studies suggest that employers in, for instance, Japan encourage employees to get married as a means to retain them (Miyoshi, 2013). The underlying assumption is that the burden of family expenditure will increase with marriage, and employees with heavier financial burden will be easier to manage. Both Heath (1999) and Noreen (1988) observe that, due to the premise of self-interested human nature and beliefs in competitive social selection, companies tend to focus on extrinsic incentives for recruiting, selecting, maintaining, and promoting talents; consequently, continuous bargaining and conflicting relationships between the owner and managers are normal. All of these can be readily observed in the firms that I looked at. 


\section{The Joy and Set-Back of the Chosen Ones in Milking the Stock Market}

In June 2015, the second time I visited Quanzhou, the Chinese stock market was experiencing an unprecedented crash. A third of the value of A-shares on the Shanghai Stock Exchange was lost within one month. The Guardian compared this pattern of losses to the Wall Street Crash of 1929 (August 25, 2015). Many informants were in a state of extreme anxiety because their money was trapped in the stock market, although they were expecting a better economy in China soon.

On the second day after my arrival, coordinated by Liu Jun, the VP of a manufacturing company, I had the opportunity to have dinner with Wang Zong, Li Xing, Yang Feng, and Yang Yi, all CFOs of listed companies. In Quanzhou, manufacturers are encouraged by local officials to engage in initial public offerings (IPOs) and seek listings on stock exchanges to raise capital for expansion. The purpose of IPOs, according to the majority of my informants, is to collect money (quanqian). Over dinner, I asked them to describe the purpose of IPOs. Liu Jun stated:

We have been having regular gatherings recently to share information regarding the performance of the stock market: the bull market (niushi) and the bear market (xiongshi). Mostly, our topic was IPOs. I have been seeing so many bosses, managers, university classmates, ex-colleagues, and acquaintances who are successful in accumulating a large amount of personal wealth, through participating in the process of companies' IPOs. Normally, the purpose of these companies' going public is to collect money (quanqian) for their self-interest. Banks don't trust private companies. They would not provide timely help (xuezhongsongtan).

Raising capital through IPOs helps to overcome the difficulty medium-sized firms have with obtaining loans from Chinese banks. Many of these companies have listings on stock exchanges in Shanghai or Hong Kong. IPOs have become a major component in the business planning of many small and medium-sized companies.

Reflecting on the public discourse before the reform era, when money was seldom seen as a concern, some argue that the phenomenon then is a demonstration of ideals about economy and human nature premised on denial of basic human desires, which is "unscientific" (Hong, 2004; Osburg, 2013; Shapiro, 2001). Confucius says the small person (xiaoren) is attached to money (xiaorenyuyuli) and being overly attached to money is often regarded as xiaoren. If the Chinese people were urged to be junzi rather than a small person, why then the obsession with money?

Now, the term "money" is popular in the public discourse and featured highly in my informants' narratives. "Rich and bitch" (youqianjiushirenxing) was one of the top-ten cyber catchwords in 2014. Since the reform era, money matter has become ingrained in the process of accumulation of wealth, power, and status, which is regarded as the major part of personal achievement (Osburg, 2013; Yang, 1994). According to the majority of informants and my observation, managers are fundamentally motivated by a desire to accumulate wealth during the process of IPOs. Although a few informants mentioned that the motivation is to have the IPO experience, it is a bright future career with a higher possibility of accumulating more wealth which is calling the ultimate shot because their resume will be more attractive to potential employers with IPO experience or with IPO plan.

If there is a chance to be a member of the IPO team of a company, in charge of either finance, law, or investment issues, the manager will potentially earn a large amount of money after the IPO. They will be granted a portion of the company's stocks, which will most likely make them to accumulate a lot of money. Liu Jun explained: 
Normally professional managers' total annual remuneration will be more than 1 million yuan. After working several years in a listed company, they will accumulate several million yuan in wealth. Afterwards, these managers will resign from their current job and join smaller-sized and innovative firms, as these companies will go public in the future which would then provide them with a chance to accumulate even more wealth.

Mr. Wang Zong, the owner of a consulting company, is one such example. In the 1990s, he had the opportunity to assist in several companies’ IPOs. Liu Jun explained to me privately:

According to my estimation, Wang Zong's cash in hand might amount to several hundred million yuan. Thirty years ago, Wang only earned a monthly salary of about 100RMB in a governmental department. The reason why I often invite him for banquets is to build relations with him and access to information of listed companies and the stock market. To build relations with him is not so easy. I need to invite him several times and spend a lot of money on eating, karaoke, and massage. Then, he and his friends will start to trust me and I will eventually join their social circle (quanzi) and become one of them.

The point about being overly attached to material achievement is that such attachment originates from the traditional mode of thinking: to glorify the family (Wilson \& Pusey, 1982). Ingrained in managers' mental model is the belief that to be a person with responsibility (youzerengan), especially for the family, is unquestionable and unshakable (Osburg, 2013; Smith, 1897). Further, since the reform and door opening policy, the Western formulation of individualism and consumerism also has its impact on managers' way of thinking; and its expression — to have good cars, bigger houses, and other forms of personal wealth—is a major way to represent their social status, power, or competence.

Also, this finding is compatible with the notion that humans are conceived as highly individualistic and relationships with their peers are conceived as little more than means to an end. Naturally, the purpose of company, family, and individual are all directed towards the ability to survive, in a calculated and self-maximizing manner.

Achievement in its material aspect is also emphasized by the government's economic policies. For example, the China Securities Regulatory Commission selects enterprises that are suitable for IPOs, the criteria being the growth rate of revenue and profit. The Local governments also regard GDP as the only indicator of their performance. As for the firms, the rate of growth is used to gauge a company's health. Further, to do well materially (guodehao) is the ultimate goal for most individuals and families. The dictate to focus on the material aspect of development through expansion and increasing productivity is consistent with the self-interested homo economicus and Weber's rational instrument (Zhang, 1997). The basic assumption is that human is, by its animal nature, characterized by greed and aggressiveness.

\section{A Simple and Quiet Life as a Form of Luxury}

In addition to the discourse on real estate and the stock market, another phenomenon that attracted my attention was the pursuit of a sense of self-meaning at many levels of society, including managers. Some managers turn avidly to Chinese classics and spiritual activities in order to explore the wisdom of life. The first day I visited Quanzhou, Lin Jin introduced me to another informant Mr. Chen Jin, who is just starting an incense business. The reason he chose this business is that he found more and more managers are interested in a slow and peaceful life, focusing more on their inner life or a more spiritual pattern of life. Also, more companies are introducing organizational training programs in spiritual activities such as incense practice or other aspects of traditional culture. Mr. Chen Jin said: 
Compared with the last century, Chinese managers nowadays show more interest in spiritual matters in their leisure time. Many of them would spend time reading Chinese classics, practicing calligraphy and painting, learning yoga, tea ceremony, and meditation, rather than drinking alcohol, playing cards, or singing karaoke.

Zheng Xin told me a story about his one-week stay in a temple:

I feel that I am a real human being during these seven days, without people disturbing me. There are no differences in occupational status, income, or educational attainment. There is no conflict, argument, or suspicion. The environment is full of love, care, and kindness. Nobody forces me to do what I don't want to do. One day, when I arrived late in the dining room, there was not much hot food left. They cooked a bowl of hot noodles for me immediately. I was very grateful at that moment. Just serving me a bowl of hot noodles was enough to make me happy.

In response to my question about what would make them happy in their daily life, many informants answered that the happiest time is the time spent with their family, especially their children. Mr. Lin Jin, the HR manager of a real estate company, stated:

Every day when I go home after work, I like to hear the lovely voices of my kids. They laugh all the time. By playing with them, I am not tired anymore. Those negative feelings such as anxiety, stress, or tension brought from work disappear immediately. I'd like to spend more time playing with my kids.

Meaning and inner peace appear in my informants' conversation. Social discourses of some managers are gradually shifting to topics such as yoga, spirituality, Zen Buddhism, Sinology, incense lore (xiangdao), tea ceremony (chadao), and the like. A few informants even believe that philanthropy and civil society will bring them joy. Ms. Cui Lin, the owner of a furniture company, when talking about a recent philanthropy project developed and initiated by her company, explained:

As an enterprise or individual living in this society, we need to take responsibility for the betterment of the society, either to be a volunteer or to engage in philanthropy. I myself often take some time to reflect on the ultimate meaning of accumulating so much wealth and how to obtain inner peace in my mind.

Whether it is for their own organizational or individual reputation, or seeking a more meaningful life, this constitutes a new trend in Chinese society (Wang, 2011).

But managers do have to go back to the reality of everyday life, to take care of the family, and take responsibility for their parents, children, and employees. Many of them expressed their anxiety during our conversation. Zhou Hua, Assistant Chairman in a leather company, complained:

I bought the original stock of my company ten years ago when it was going public successfully. Now the value of my stock is more than 10 million yuan. This amount of money may cover my whole family's expenditure for the rest of my life. However, I don’t know why I always feel insecure.

Life as experienced in the temple will never characterize Zheng Xin's normal life, as he has to survive in such a competitive society. He explained to me in a very depressed tone:

We might be categorized as middle class according to my family’s monthly income. I am the CFO of a big real estate company and my wife is a successful consultant. My salary is already high. She earns even more money than me. However, most of the time, I am really stressed with my work and family responsibilities. Why do I still feel insecure? It may be related to our unlimited human desire. I want more. High salary doesn't mean you will be satisfied. I hope that my next generation will not be troubled by money anymore. 
The far-reaching discussion about the meaning of life initiated by Chinese Youth in the 1980s is of significance in the modern Chinese history of thought. "Let the self be subjective, but to others, be objective" (zhuguanweiziji, keguanweibieren) became the dominant value during the years following this discourse. Throughout the 1990s, revelations of widespread corruption among party and government officials eroded any Marxist vision of hope. As ready access to consumer goods and other economic improvements spread to wider segments of the population, "socialism with Chinese characteristics" was replaced by "capitalism with Chinese characteristics". Not a few managers turn to consumerism. As Ci (1994, p. 11) put it, "in hedonism, a spirituality exhausted people found a pursuit in which the spirit did not have to participate". Consumerism offers only fragile refuge, however; the human spirit hungers for more. The new generation of managers, moving beyond the basic struggle for economic survival, cannot but confront the deeper questions of the meaning of life.

\section{Conclusion}

This study has found that the managers have adopted and internalized some concepts related to human nature, albeit unconsciously: assumption of human as animal, self-interested, Maslow's physical needs, competitive selection, and survival of the fittest; and these concepts are embedded in their intellectual framework. Such assumptions guide their managerial behaviours and individual life in such diverse aspects as the use of extrinsic incentives, strict internal control system, preferring insiders, financial strategies of IPOs, buying more properties, accumulating more wealth, or choosing high-salary companies. As these management practice and styles emanate from mangers' deeply held assumptions regarding human nature, no major change to their managerial behaviour would happen unless there is alteration to these assumptions.

The responses from many managers convey a pattern of thought, in a selective and reductive manner, directed towards a materialist conception of reality. However, confining their life pursuit to material dimension alone has not been able to satisfy their longing for a deeper sense of self-meaning and insights which might would help them to move beyond the often distorted conceptions of human nature that are nonetheless strongly held by the masses today. Having retreat at the temple, engaging in different "spiritual" activities, or spending time with children were some of the ways that were attempted in order to relieve their anxiety.

Some managers often express the view that the foremost thing in management is survival and one of the most effective conditions for survival is to earn more money. For that reason, it is easy to understand the remarkable meanings that manager respondents endow on money and survival. It does not take much analysis to realize that money matters occupy a central position in their thinking. Naturally, the topic of money emerged quickly and repeatedly in the early stage of my fieldwork, and its importance was widely accepted by the majority of my informants. At the same time, for them, life has to be interpreted through "the need to struggle for survival”, as individual, family, company, and employees all have to struggle for a better life-a better material life. It is taken for granted that if a company does not earn sufficient profit, if a family or individual does not possess enough wealth, they will not be able to survive in this competitive society.

The majority of informants are however unconscious of their deeply held assumptions regarding human nature, and know little about these assumptions' existence, formation, evolution, outcomes, and implications. As a result, many informants have been in a state of stress, confusion, and anxiety, as the incoherence of their mental model often generates in them some level of cognitive dissonance (Festinger, 1957). By understanding that different assumptions about human nature will result in different organizational and managerial actions, 
managers will be more conscious of how and why they are employing certain policies in terms of incentive, motivation, selection, controlling, and planning, among others. Also, they might be able to strive toward greater coherence in their individual and organizational life, and be more conscious about the foundation of that coherence.

Conceptions of human nature and its application in management are molded by their own social structure, even as they concurrently shape that structure, as framing is considered to be interactional co-constructions, rather than isolated and individual knowledge structures (Dewulf, Gray, Putnam, Lewicki, Aarts, Bouwen, \& Van Woerkum, 2009). For example, from childhood our respondents are taught in the family and in school to compete against the best. They are taught to behave properly, in all these areas, in accordance with the conception of filial piety, wulun (the Five Cardinal Relations), and the purpose of glorifying the family. There is a strong belief that one must be distinguished from others. The pursuit of distinction depends greatly however upon the wealth factor: to be more affluent than other people. Therefore, the pursuit of financial freedom and zhuanchi (to work for money) is regarded as mandatory. The fact that the value of a person is dependent on the level of material wealth that he or she possesses is a reflection of the dominant conception of human nature that was discussed above. To be sure, one would expect that different conceptions of human nature might from time to time present themselves as alterative candidate but in the current condition, the entire culture is in favour of only one conception of human nature, and there is no space for an alternative or competing notion of human nature. In fact, all the forces and instruments of culture are at work to ensure that the dominant one is perpetuated and all the rest marginalized.

This finding has also demonstrated a simple truth: the triumph of homo economicus over traditional Chinese conception of human nature. But it would be incorrect to say that the essential elements of the former were totally absent in the latter. Indeed, there present in the traditional Chinese philosophy the altruism and self-interestedness notion of human being but the recent experimentation of China with socialism and market economy has advantaged homo economicus; the outcome being that the conception of human nature which is self-interested and competitive is what guide and shape the Chinese managers in this study.

Further, not only are the managers imprisoned by their own thoughts, it is also difficult for them to come up with alternative or unique thoughts as they, as a social group, are so closely linked in their social and professional lives, and that they are all immersed in a common and dominant culture, which promulgates a single thought system only. The social nature inherent in our cognitive activities is relevant here. Fleck (1981, p. 46) argues that:

What actually thinks within a person is not the individual himself but his social community. The source of his thinking is not within himself but is to be found in his social environment and in the very social atmosphere he "breathes". His mind is structured, and necessarily so, under the influence of this ever-present social environment, and he cannot think in any other way.

For this reason, we are not optimistic that change in thinking that is revolutionary in nature would emerge in the near future. Consequently, no dramatic change of management style would be expected.

What this study has tried to demonstrate is the power of thought, particularly assumption, on both individual and collective behaviour. The present endeavour is confined to assumptions about human nature. Naturally, there are many other assumptions that are animating, if not limiting, managerial behaviours. Other categories of assumption might include the nature of relationships among the individual, institutions and 
community; power; the source of knowledge; justice, and so on. These assumptions would surely impact as potently on the lives of managers, as has been shown for assumptions about human nature in this study; and this would surely be a fertile area for research for students of management.

\section{References}

Abdu’l-Bahá. (1969). Paris talks: Addresses given by Abdu’l-Bahá in Paris in 1911 (11th ed.). London: Bahá'í Publishing Trust. Agar, M. (1996). The professional stranger: An informal introduction to ethnography. San Diego: Academic Press.

Aglietta, M., \& Guo, B. (2012). China's development: Capitalism and empire. London: Routledge.

Argyris, C. (1964). Integrating the individual and the organization. New York: John Wiley.

Argyris, C. (1976). Increasing leadership effectiveness. New York: John Wiley.

Argyris, C. (1982). Reasoning, learning, and action: Individual and organizational. San Francisco, CA: Jossey-Bass.

Bohm, D. (1994). Thought as a system. London and New York: Routledge.

Chen, G. M. (2000). The impact of harmony on Chinese conflict management. Proceedings from the Annual Meeting of National Communication Association, Seatle, Washington, November 8-12, 20.

Chen, W., \& Zhang, Z. W. (2013). China: Rising risks of financial crisis. Asia Special Report. Hong Kong, Nomura Global Economics, March 15.

Ci, J. W. (1994). Dialectic of the Chinese revolution: From utopianism to hedonism. Stanford: Stanford University Press.

Dardes, J. (1991). Childhood in pre-modern China. In J. M. Hawes, \& N. R. Hiner (Eds.), Childhood in historical and comparative perspective (pp. 71-94). New York: Greenwood.

Dewulf, A., Gray, B., Putnam, L., Lewicki, R., Aarts, N., Bouwen, R., \& Van Woerkum, C. (2009). Disentangling approaches to framing in conflict and negotiation research: A meta-paradigmatic perspective. Human Relations, 62, 155-193.

Ding, A, D. (2012). Further study of China's housing price-to-income ratio. Advances in Applied Economics and Finance, 2(4), 433-436.

Effendi, S. (1933). Letter written on behalf of Shoghi Effendi, 17 February 1933, Compilation on Social and Economic Development. Retrieved from https://bahai-library.com/pdf/compilations/development.pdf

Eisenberg, E. M. (1984). Ambiguity as strategy in organizational communication. Communication Monographs, 51, $227-242$.

Ferraro, F., Pfeffer, J., \& Sutton, R. I. (2005). Economics language and assumptions: How theories can become self-fulfilling. The Academy of Management Review, 30(1), 8-24.

Festinger, L. (1957). A theory of cognitive dissonance. Evanston, IL: Row \& Peterson.

Fleck, L. (1981). Genesis and development of a scientific fact. In T. Trenn, \& R. Merton (Eds.), University of Chicago Press, Chicago.

Fong, V. (2007). Morality, cosmopolitanism, or academic attainment? Discourses on "quality" and urban Chinese-only-children's claims to ideal personhood. City \& Society, 19(1), 86-113.

Frank, R. H. (1988). Passions within reason: The strategic role of the emotions. New York: Norton.

Hahn, C. K., \& Waterhouse, W. C. (1972). Confucius theories of man and organization. Academy of Management Journal, 27, 166-175.

Harvey, D. (2005). A brief history of neoliberalism. New York: Oxford University Press.

Heath, C. (1999). On the social psychology of agency relationships: Lay theories of motivation overemphasize extrinsic incentives. Organizational Behavior and Human Decision Processes, 78, 25-62.

Hofstede, G., \& Bond, M. H. (1988). The Confucius connection: From cultural roots to economic growth. Organizational Dynamics, 16(4), 5-21.

Hong, D. Y. (2004). Social assistance in China during market transition. Shenyang: Liaoning jiaoyu chubanshe.

ISGP (Institute for Studies in Global Prosperity). (2005). Science, religion, and development: Some initial considerations. New York: Bahai International Community.

La Grange, A., \& Pretorius, F. (2000). Ontology, policy and the market: Trends to home-ownership in Hong Kong. Urban Studies, 37, 1561-1582.

Legge, J. (1970). The works of Mencius, 1895. Reprint, New York: Dover.

Li, Y. (2013). Traditional Chinese thinking on HRM practices: Heritage and transformation. London: Palgrave Macmillan.

Madsen, R. (2011). Religious renaissance in China today. Journal of Current Chinese Affairs, 40(2), 17-42.

Maslow, A. H. (1954). Motivation and personality. New York: Harper. 
McGreal, I. P. (1995). Great thinker of the Eastern world. New York: Harper Collins.

McGregor, D. M. (1985). The human side of enterprise. New York, NY: McGraw-Hill.

Miyoshi, K. (2013). The labor market and marriage decisions in Japan. The Japanese Journal of Labour Studies, 55(9), 33-42.

Noreen, E. (1988). The economics of ethics: A new perspective on agency theory. Accounting, Organizations and Society, 13, 359-369.

Osburg, J. (2013). Anxious wealth: Money and morality among China's new rich. Stanford: Stanford University Press.

Ouchi, W. G. (1981). Theory Z. Reading, MA: Addison-Wesley.

Pei, M. X. (2006). China's trapped transition: The limits of developmental autocracy. Cambridge. Mass.: Harvard University Press.

Powdermaker, H. (1967). Stranger and friend: The way of an anthropologist (1st ed.). New York: W. W. Norton \& Company.

Roethlisberger, F. J., \& Dickson, D. W. (1939). Management and the worker. Cambridge, MA: Harvard University Press.

Sabanci, A. (2008). School principals’ assumptions about human nature. Educational Management Administration \& Leadership, 36, 511-529.

Schein, E. H. (2004). Organizational culture and leadership (3rd ed.). San Francisco, CA: Jossey-Bass.

Senge, P. (2006). The fifth discipline. New York: Doubleday.

Shapiro, J. (2001). Mao's war against nature: Politics and the environment in revolutionary China. New York: Cambridge University Press.

Smith, A. ([1776] 1986). On the division of labour: The wealth of nations. New York: Penguin Classics.

Smith, A. H. (1897). Chinese characteristics. New York: The Caxton Press.

Spradley, J. P. (1979). The ethnographic interview. New York: Harcourt College Publishers.

Tisdell, C. (2009). Economic reform and openness in China: China's development policies in the last 30 years. Economic Analysis and Policy, 39(2), 271-294.

Wang, H. (2003). China's new order: Society, politics, and economy in transition. (T. Huters \& R. E. Karl. Trans.). Cambridge, Mass.: Harvard University Press.

Wang, M. (2011). Emerging civil society in China, 1978-2008. Leiden: Brill.

Weick, K. E. (1995). Sensemaking in organizations. Los Angeles, CA: Sage.

Wilson, R. W., \& Pusey, A. W. (1982). Achievement motivation and small business relationship patterns in Chinese society. In S. L. Greenblatt, R. W. Wilson, \& A. A. Wilson (Eds.), Social interaction in Chinese society (pp. 195-208). New York: Praeger.

Yang, M. M. H. (1994). Gifts, favors, and banquets: The art of social relationships in China. Ithaca, N.Y.: Cornell University Press.

Yu, J. (2007). The ethics of Confucius and Aristotle: Mirrors of virtue. New York: Routledge.

Zeng, S. Q. (2006). The middle way management: $M$ Theory and its application. Peking: Peking University Press.

Zhang, D. S. (1997). Si ru feng yun: Xian dai Zhong guo de si xiang fa zhan yu she hui bian qian (Intellectual development and social transformation in modern China). Taibei: Ju liu tu shu gong si.

Zhang, Y. Y., \& Simon, D. (2009). Management by values: A theoretical proposal for strategic human resource management in China. Chinese Management Studies, 3(4), 272-292.

Zohar, D. (2004). Spiritual capital. San Francisco: Berrett-Koehler. 